\title{
Artelogie
}

artelogie Recherche sur les arts, le patrimoine et la littérature de I'Amérique latine

$11 \mid 2017$

Délocalités, translocalités et activisme dans l'art électronique et biomédiale latino-américain

\section{Lenguas migrantes y desvíos críticos en The 27th // El 27th de Eugenio Tiselli}

Verónica Paula Gómez

\section{OpenEdition}

Journals

Edición electrónica

URL: http://journals.openedition.org/artelogie/1485

DOI: 10.4000/artelogie. 1485

ISSN: 2115-6395

Editor

Association ESCAL

Referencia electrónica

Verónica Paula Gómez, «Lenguas migrantes y desvíos críticos en The 27th // El 27th de Eugenio Tiselli », Artelogie [En línea], 11 | 2017, Publicado el 01 diciembre 2017, consultado el 02 mayo 2019. URL : http://journals.openedition.org/artelogie/1485; DOI : 10.4000/artelogie.1485

Este documento fue generado automáticamente el 2 mayo 2019.

Association ESCAL 


\title{
Lenguas migrantes y desvíos críticos en The 27th // El 27th de Eugenio Tiselli
}

\author{
Verónica Paula Gómez
}

\section{Desvíos de lo inmutable, tres lecturas}

1 Este trabajo se concentra en analizar el uso político de lenguajes -verbal, visual, algorítmico- en diversos discursos -técnico, legal, intertextual- que integran la obra de literatura electrónica The 27th // El 27 de Eugenio Tiselli (2014). Lo que a primera vista aparece como parte de un texto inamovible, un artículo de la Constitución del Estado mexicano, adquiere carácter literario mediante la tergiversación técnica de la letra de la ley en múltiples desvíos. En este sentido resulta apropiado pensar aquí en migraciones de las lenguas que desestabilizan la especificidad de la literatura, desafiando sus límites (Kozak, 2006) al mismo tiempo que se inmiscuyen de lleno en la arena política y desbordan el paisaje moderno (Appadurai, 2001) propio del derecho positivo.

The 27th // El 27 es una obra de literatura digital que propone una discusión en torno a lo que el autor llama la política algorítmica. La obra reproduce el artículo 27 de la Constitución mexicana que trata sobre la propiedad de la tierra y los recursos naturales de ese país. En la pantalla aparece la reproducción del artículo en español en color negro y la traducción automática de palabras en color rojo. En la parte superior se encuentra a la izquierda una breve descripción de la obra en español y en inglés, con un link que redirige a una página en donde se amplía el concepto de la obra y a la derecha un recuadro con información relativa a la Bolsa de Valores de Nueva York, en verde cuando está en alza y en rojo cuando está en baja. De este binarismo dependerá la traductibilidad, como explicaremos más adelante. 


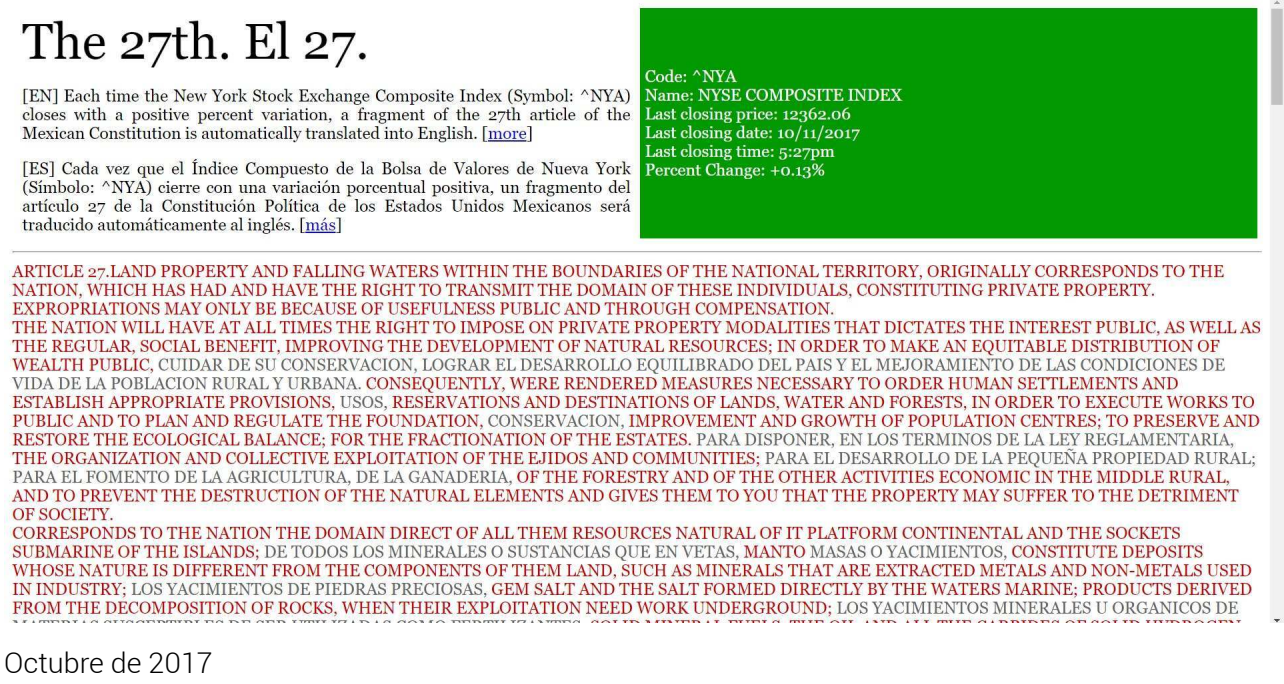

EUgENIO TISELLI

Se trata de una producción en la que su autor propone que "cada vez que el Índice Compuesto de la Bolsa de Valores de Nueva York cierre con una variación porcentual positiva, un fragmento del artículo 27 de la Constitución Política de los Estados Unidos Mexicanos ${ }^{1}$ será traducido automáticamente al inglés" (Tiselli, 2014: s/p). Observamos que Tiselli despliega una tecnopoética (Kozak, 2015) que involucra algunas de las controversias actuales socio-económicas, culturales y políticas en las que se ubica México, de modo subordinado, en relación con Estados Unidos, teniendo en cuenta que el artículo de origen legisla sobre el dominio de las tierras y aguas y la propiedad privada dentro de los límites del Estado mexicano. En este sentido, aquí argumentamos en torno a tres lecturas posibles que se integran entre sí en un contexto propio de la cultura visual global contemporánea.

En una primera lectura advertimos el uso dual y subordinado de idiomas (español-inglés) como símbolo de apropiación de la Nación mexicana, modificándose con cada palabra traducida, su órgano máximo de orden legal, la Constitución. Con este procedimiento, "the quality of natural language is reduced. Spanish from the time the Mexican Constitution was written tends to dissapear" (Kozak, 2017: 65). Esto nos remite al planteo marxista de la relación de propietarios de los medios de producción y trabajadores alienados hasta el punto en que al traducir la lengua original a la del apropiador, se quita la posibilidad de hablar, característica de lo humano. ¿Qué efectos provoca la intromisión codificada de la economía en la lengua de la política? El texto fuente, la Constitución, aparece intervenido a partir de la traducción mediante lo que el autor llama una "política algorítmica" que en su propia dureza y alejamiento mecanicista, propone una poética tecnológica basada en la supremacía de la lengua económica por sobre la de la política.

5 A esa primera "migración" se integra una segunda, en un lenguaje visual en el que aparece el texto en dos colores, negro (base en español) y rojo (cambios en inglés), como si en cada palabra traducida se realizara la perforación de un cuerpo, imagen sangrante cuyo dolor crece cuanto más inequitativa se vuelve la distribución de la riqueza bajo la actual dictadura financiera (Berardi 2014). Y de allí también nace la sangría de migrantes mexicanos hacia el norte. ¿Cómo decir el dolor de las masas como cuerpo sin voz 
atravesando el camino de las promesas incumplidas del "progreso" moderno? Con esto se hace hincapié en la materialidad de la letra y su aspecto corpóreo y "viviente" que permite constantes cambios en línea.

6 Por último, proponemos una lectura sobre el tema de la propiedad privada, en particular de los recursos naturales, del que habla el artículo 27. Al haber elegido este artículo, Tiselli hace del lenguaje de la técnica necrocapitalista al que nos referiremos más adelante, un uso insumiso (Brea, 2002) que a partir de la interacción con una variable "objetiva" traída de la economía, migra de la determinación mecanicista hacia la techné entendida como poética (Schmucler, 1996) es decir, el autor se sirve del elemento económico para desarrollar su obra artística. ¿Cómo vincular ese dominio del discurso legal-racional basado en la técnica con un régimen de sensibilidad que pareciera, a primera vista, ausente en un artículo constitucional? En este desvío, Tiselli elabora sus estrategias de insumisión con la materialidad intrínseca al discurso de la ley: hace migrar en tecnopoética la lengua del discurso jurídico, a priori invariable y racionalizado en un alto nivel de abstracción terminológica propio de la idea de "progreso" moderno sobre la que se construye.

\section{La traductibilidad del necrocapitalismo}

7 La primera lectura que sostenemos se relaciona con la llamada "política algorítmica" que sustenta esta obra en la forma de una paradoja dada por la traducción automática entre idiomas (español e inglés). Es justamente esta poética maquinal (AAVV, 2006-2016) la que permite socavar y "hundirse en las llagas" que provoca la dictadura financiera (Berardi, 2014) que domina y destruye el carácter de lo humano en pos del mecanicismo necrocapitalista.

8 El actual periodo de globalización neoliberal puede ser caracterizado como capitalismo gore o necrocapitalismo, lo que implica que el crecimiento financiero y la acumulación económica son inseparables del aumento de la producción global de muerte. (Banerje, 2010 en Emmelhainz, 2015: s/p).

9 Lo paradójico resulta de la propiedad del lenguaje financiero, que se presenta "en forma de un bucle de retroalimentación negativa, es decir: un proceso relacional en el cual, mientras que uno de los actores de la relación se amplifica y expande (la economía), el otro se somete y debilita (el lenguaje)" (Tiselli, 2012-2014: p. 132). Tal como él mismo señala en el artículo que aparece vinculado a la obra, el intento de Tiselli no es detener ese bucle sino por el contrario, acelerarlo para llevar al límite sus efectos y explicitar críticamente la destrucción del lenguaje colectivo, el del espacio público que remite a la política, y su reemplazo por la atomización algorítmica de la economía, lenguaje aplanado e intervenido por múltiples mutilaciones maquínicas. La lengua que se habla colectivamente es engullida por la máquina diseñada por el necrocapitalismo y nos desafía: ¿cómo revertir el automatismo mortífero de la codificación económica en la lengua del imperio?

10 En esta misma línea, el experimento de política algorítmica de Tiselli que conecta la Bolsa de Valores de Nueva York con los cambios en la Constitución, no sólo apela a la traducción automática como modo de establecer una crítica al sistema financiero global con las propias herramientas mecanicistas con las que cuenta, sino que en ese mismo movimiento postula una jerarquía de lenguas en donde el inglés, idioma comodín de la 
maquinaria financiera, subordina al español de la Constitución en tanto lengua en la que está escrita y particularizada la política mexicana en este caso. Tiselli denuncia que la intromisión codificada de la economía en la lengua de la política renuncia a lo propiamente humano, la posibilidad de hablar, ya que algorítmicamente, la traducción maquínica supone la instrumentalización de la lengua "hasta dejarla irreconocible: rasgada, explotada, medio muerta" (Tiselli 2012-2014: p. 133). Así, traducir la lengua de origen a la lengua del imperio enmudece a sus hablantes y con ello los ubica en una relación de alienación: los propietarios de los medios de producción -diremos ahora los flujos de capital financiero volátil- se apropian de la posibilidad de decir de quienes trabajan las tierras y recursos naturales sobre las que el artículo 27 legisla.

El enmudecimiento humano a raíz de la lengua de la economía corroe los lazos colectivos y remite a una pregunta filosófica que recorrió la producción intelectual de Marx: ¿por qué el hombre es esclavo del hombre? El problema de la enajenación cobra especial atención al observar el avance del modo de producción capitalista en el siglo XIX en el transcurso de la Segunda Revolución Industrial que para Marx fue obviado por el liberalismo clásico. Esa elipsis buscó la condición de ahistoricidad de acumulación de la riqueza y desvió la atención de "la pobreza de la gran masa" (Marx, 2004: p. 892) que trabajaba bajo condiciones infrahumanas en las fábricas, suspendiendo las relaciones vitales de esos hombres. En este sentido, el tenor de lo propiamente humano queda supeditado a un modo de producción capitalista cuya concentración originaria supone riqueza para pocos y empobrecimiento y hambruna para la mayor parte de las masas populares. A nuestro entender, lo anterior se vincula con la obra de Tiselli por el fuerte hincapié del debate sobre a quiénes es funcional el mentado "progreso" técnico que cobra fuerte impulso ${ }^{2}$ en el siglo XIX y que no ha sido saldado sino, por el contrario, se encuentra vigente en el tipo de producciones como The 27th // el 27 al advertir el accionar del capital financiero y la negación de los sujetos que la sustentan. Así, donde el positivismo lee progreso y ubica a la ciencia como la encargada de promulgar las leyes para el entendimiento en un giro con cierto matiz de neutralidad exculpatoria (Brea, 2002: s/p), el marxismo se preguntará por las relaciones que median entre los sujetos implicados en esos cambios y una de las respuestas que dará será la necesidad de historizar el fenómeno, en particular de la acumulación originaria (Marx, 2004), que permite este desarrollo mecanicista del modo de producción capitalista para comprender de esta manera, la relación de enajenación (y su consecuente objetivación mercantilista) que niega la naturaleza humana. Al mismo tiempo, en línea con la raigambre conflictivista en la que se inscribe el marxismo, es necesario aclarar que en el proceso de acumulación originaria se desata el conflicto social. De allí que nos encontremos con la dinámica estructural de las sociedades que permiten su "evolución", concepto que acerca esta teoría al modelo positivista darwiniano de las ciencias naturales, en particular, la biología.

12 Retomando el análisis de la obra que nos interesa aquí, habría un paralelo entre la elipsis histórica del liberalismo clásico que observa Marx y el accionar del capital financiero actual. Este último prescinde de una reflexión sobre la técnica al presentarla como cálculo y naturalizarla en tanto mero instrumento: "La técnica moderna, en su voluntad de hacer previsible el futuro, postula un borramiento de límites, una natural artificialización, que indiferencia al hombre" (Shmucler, 1996 : p. 2). Tiselli se subleva, en esta dirección, sobre lo cristalizado de ese desarrollo "neutral" haciendo explícita la ideología que se aloja en la abstracción financiera. 
13 La lengua, espacio donde habita la metá-fora - "ir más allá" - (Schmucler, 1996) y por lo mismo, reserva humana de lo incalculable e imposible de asir ante la matematización del mundo moderno, sustenta su desafuero creativo precisamente en los números, que según Tiselli son el "instrumento preferido de ciertas tiranías para ejercer su poder, también pueden ser usados en su contra. Y porque tal vez son los números, precisamente, el material poético que denuncian de forma más clara los tiempos de horror que nos están haciendo pasar" (2012-2014, p. 22). Es en la apuesta por el uso instrumental donde radica la potencia crítica del desvío ya que la herramienta del imperio financiero y su lingua franca, el inglés, se ponen al servicio de una poética experimental en donde el algoritmo atraviesa las posibilidades que utópicamente aún pueden preservar la antigua esfera política de lo colectivo ${ }^{3}$. El cálculo propio del modo de producción capitalista somete a la optimización de los recursos a costa de volver inviable la legalidad de la ley, pero al mismo tiempo se presenta "como punto de partida hacia una alternativa viable que, desde la resistencia, puede abrir nuevos caminos" (Tiselli, 2012-2014: p. 56).

14 ¿Qué lengua hablan las máquinas? ¿Quién les enseña a hablar la lengua del Otro? Si ahora volvemos a la disputa español-inglés, falta agregar aquí que la especificidad de la lengua de escritura importa sobre todo porque la traductibilidad juega en dos direcciones. Primero, hacia el vaciamiento de la lengua original -el español- que compite en el plano interlingüístico por su supremacía y cantidad de hablantes con la lengua de llegada -el inglés-. Y segundo, hacia la tergiversación errática que se provoca dada la desinvestidura del algoritmo como traducción maquínica, y consecuentemente, como lengua de una política no humana. En cualquier caso, el maestro de la máquina es el capital financiero pero el artista se rebela y provoca, con ese conocimiento lingüístico adquirido, una desviación crítica.

\section{Cuerpos migrantes, letras sangrantes}

15 La migración entre lenguas antes desarrollada no se detiene solo en hacer cosas con palabras, también y sobre todo, afecta a los cuerpos insertos en el necrocapitalismo. Algoritmos financieros en alza y cuerpos muertos se vinculan exponencialmente: cuanto mayor sea la variación porcentual positiva del Índice Compuesto de la Bolsa de Valores de Nueva York, mayor será la presión sobre enormes poblaciones migrantes que mendigan un lugar en los bordes de un sistema cada vez más inequitativo. The 27th // El 27 intenta visibilizar esa distribución mortífera de la riqueza con un lenguaje visual binario. En este sentido, los idiomas implicados pasan a un segundo plano y cobran especial atención las incisiones en el cuerpo de la letra constitucional. Dos colores dominan el texto: negro (base en español) y rojo (cambios en inglés). Cada palabra mutilada por la traducción maquínica supone el avance de la perforación del necrocapitalismo en esos cuerpos devastados que pierden la voz: "lo colectivo se vuelve cada vez más inimaginable, y los individuos se convierten en autómatas celulares en cuyo cuerpo mismo ya están inscritos tanto el código del comportamiento económico como el lenguaje plano y mutilado que requiere el capital para operar sin fricciones" (Tiselli, 2012-2014: p. 134).

16 Palabras rojas y negras corporizan dos estados entre los que se halla la frágil masa humana migrante. La materialidad de la letra se pone de relieve, haciendo manifiesta la crítica hacia la lengua letal de la economía. Por un lado, el necrocapitalismo necesita capital humano viviente sobre el que ejercer su dictadura financiera para explotar territorios y recursos, pero, por otro lado, se sustenta en la destrucción de esas vidas 
precarias como materia fácilmente reemplazable y anónima, de allí el negro del texto fuente, sobre el que se ciñe el bisturí inimputable de los algoritmos cuya sangre sintetiza el color rojo del avance del inglés. El estado del cuerpo migrante -de la lengua y de las masas que físicamente se desplazan a diario hacia los bordes en busca de un "un futuro mejor"- se halla descompuesto, plegado, comprimido e incapaz de manifestar su potencia verbal, afectiva, física y social (Berardi, 2014).

Figura 2: Captura de pantalla de The 27th // El 27

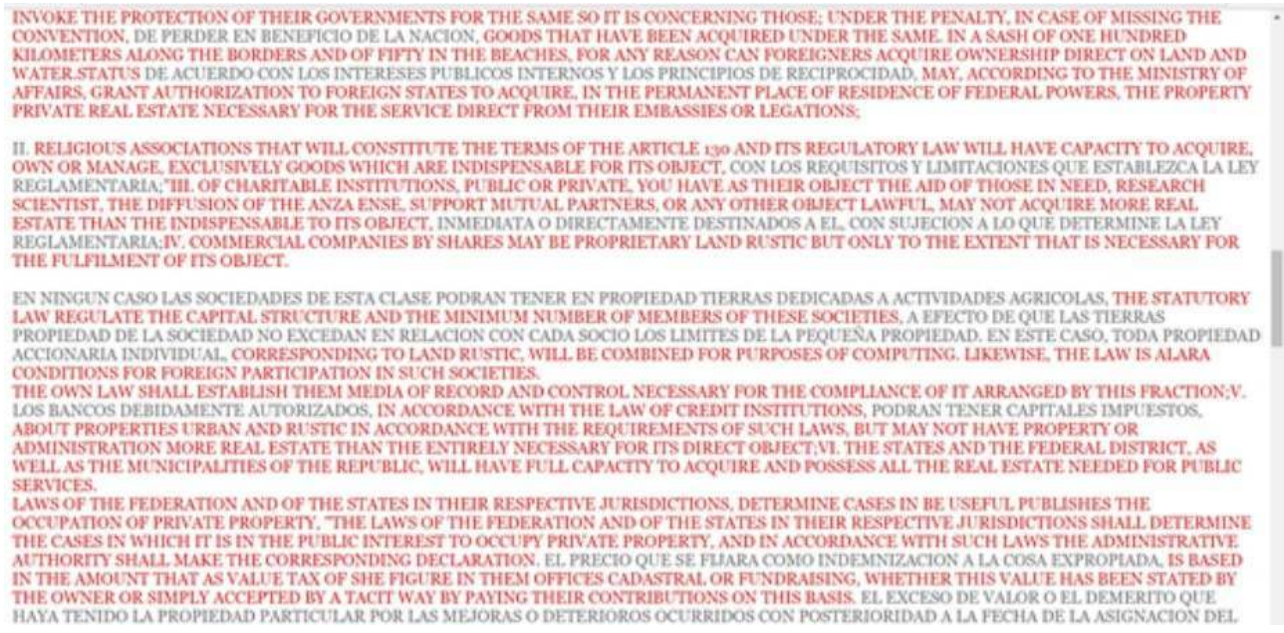

OCTUBRE DE 2017

EUgENIO TISELLI

17 ¿Qué posicionamiento político le cabe a la literatura cuando las perforaciones sangrantes avanzan sobre los cuerpos enmudecidos? ¿Qué hacer con el cuerpo de palabras violentadas por la lengua del automatismo financiero? En su libro La sublevación (2014), Berardi afirma que: "La acción social, la decisión democrática, el discurso público pierden toda eficacia cuando la potencia financiera redefine todos los parámetros e impone sus prioridades" (p. 117). Esas prioridades consisten en la captura y vaciamiento del lenguaje a favor de la aceleración especulativa y vacía del necrocapitalismo, que ocupa las corporalidades, las perfora y las desecha mecánicamente. Siguiendo este planteo y en el marco del colectivo poesía maquinal al que pertenece el autor, la producción de Tiselli apunta a una re-sensibilización de lo humano provocando una desviación de "la operatividad abstracta y autómata de las finanzas" (AAVV, 2006-2016: s/p). Con ello ubica políticamente su poética en torno a un desplazamiento hacia las lindes de la literatura (Kozak, 2006):

(...) ante la imposibilidad de regresar inmediatamente a una utilización premoderna del lenguaje con el fin de aliviar el dolor del significante y restaurar sus vínculos con el significado. Así pues, la poesía maquinal mete el dedo en la llaga para hacer más profunda y dolorosa la herida, buscando hacer aún más abstracta nuestra relación con el mundo mediada por el lenguaje. (AAVV, 2006-2016: s/p).

Por otro lado, dentro del lenguaje verbal que compone el artículo 27, lo único que queda idéntico en la traducción son los números romanos y los signos de puntuación, privilegiándose así la codificación numérica que envuelve el texto por sobre la variabilidad y la pérdida que sufre en su traducción del lenguaje verbal. Lo mismo pareciera suceder en cuanto a las personas que migran y la Bolsa de Nueva York: lo 
inmutable dentro de la forzada traducción lingüística, corpórea, terrenal, legal es el porcentaje que arroja valores mecánicamente.

The 27th // El 27 apela a transformar la mirada sobre la ley escrita en una experiencia poética, en el sentido de un desplazamiento de la lengua del derecho hacia la corporalidad material migrante, como venimos de decir. Sin embargo, la propuesta maquínica se sustenta en una inversión de la estética definida a partir de las facultades sensoriales (Buck-Moors, $2004: 122)$ a un bloqueo "anestético": "las facultades sensoriales cambian: de estar "en contacto" con la realidad pasan a ser un medio de bloquear la realidad (...) una capacidad cognitiva enmudecedora de los sentidos que destruye el poder del organismo humano para responder políticamente incluso cuando se encuentra en juego su propia conservación" (p. 125). Así, Tiselli pareciera querer "despertar a las cosas de su sueño retraído" (Tiselli, 2012-2014: p. 61) elaborando una poética sobre la ley violentada al tiempo que, paradojalmente, ubica a su lector-usuario en una posición de impotencia: los cuerpos de los que hace uso el necrocapitalismo no dejarán de ser materia muerta en vida, no dejarán de sufrir la mutilación sangrienta de su voz, no dejarán su automatismo constituyente como masa sin distinciones sino que a mayor sufrimiento, mayores serán los cambios positivos para la Bolsa de Valores y mayores las modificaciones en la obra ${ }^{4}$.

\section{La insumisión a la ley}

20 Como ya hemos comentado, el artículo 27 de la Constitución mexicana se elige en conmemoración de los 20 años del tratado de libre comercio con Estados Unidos y Canadá (TLCAN por sus siglas en español). Es el propio Tiselli quien explica que, a partir de ese tratado, la propiedad de la tierra y de los recursos naturales, antes bajo dominio de la Nación mexicana, cambia radicalmente con la intromisión del necrocapitalismo poniendo en duda la legitimidad del texto constitucional:

21 Ahora, gracias a las distintas reformas al artículo 27, "la Nación" se arroga el derecho de transmitir el dominio de tierras y aguas (y, por consiguiente, de humanos y no-humanos que las habitan) a los particulares constituyendo la propiedad privada. El artículo 27 hoy es la alfombra roja extendida por el Estado Mexicano para recibir por la puerta grande a los flujos y algoritmos financiero-lingüísticos del necrocapital. (Tiselli, 2012 : p. 132).

22 A partir de esto, podemos hablar de una migración del territorio soberano al que apela originalmente el artículo bajo el máximo órgano legal en términos políticos y el cambio hacia la desterritorialización de los "flujos" caóticos que se manejan en el necrocapitalismo al que apela Tiselli. Bajo la ya mencionada paradoja de la política algorítmica, se plantea aquí la subversión del discurso legal, haciendo un uso de la técnica no neutral sino político (Brea, 2002). Adoptando la política algorítmica como única manera de denunciar al necrocapitalismo, se produce esta obra basada en llevar al extremo los términos binarios: utilizar la amplificación de la ventaja de la Bolsa neoyorkina para multiplicar los cambios constitucionales. Así muestra que la soberanía, asociada al Estado-Nación moderno sobre sus límites internos (Portinaro, 2003), se ve menguada cuando se la introduce de modo relacional al sistema financiero internacional que se vuelve cada vez más dominante. Sin embargo, los Estados aún poseen una potestad: la capacidad operativa de matar o dejar vivir. "Así, el verdadero poder se traslada directamente a las manos del capital, que es ahora quien ordena quién vive y 
quién muere. El poder del capital es un poder necrocapitalista que, sin embargo, es ejecutado por los funcionarios de la antigua esfera política" (Tiselli, 2012-2014: p. 134).

La operación de Tiselli consiste en una estrategia de subvertir estas facultades de la esfera política que recaen sobre la soberanía perforadora de lo viviente: genera una desviación crítica a partir de un software basado en la propia técnica del necrocapitalismo dando lugar a "una literatura que abisma la palabra poética en otra cosa que no se sabe bien cómo llamar: experiencia artística que ha perdido sus fueros desaforada decíamos- pero que se resiste también a ser integrada a la estetización de la vida cotidiana publicitaria" (Kozak, 2006: p. 147). Esta forma paradojal de desnaturalizar la instrumentalización con el propio instrumento criticado puede ser considerada bajo el régimen de la insumisión en tanto tensamiento técnico: "No abandonándose a la sumisión que determina su forma tecnológica como forma despotenciada de expresión de un orden de cosas muerto (...) el pensamiento se revela en su verdadera naturaleza alumbratoria, vidente." (Brea, 2002 : s/p).

Figura 3: Captura de pantalla de The 27th // El 27. A la derecha con el índice de la Bolsa de NYC en baja (rojo) y a la izquierda en alza (verde)
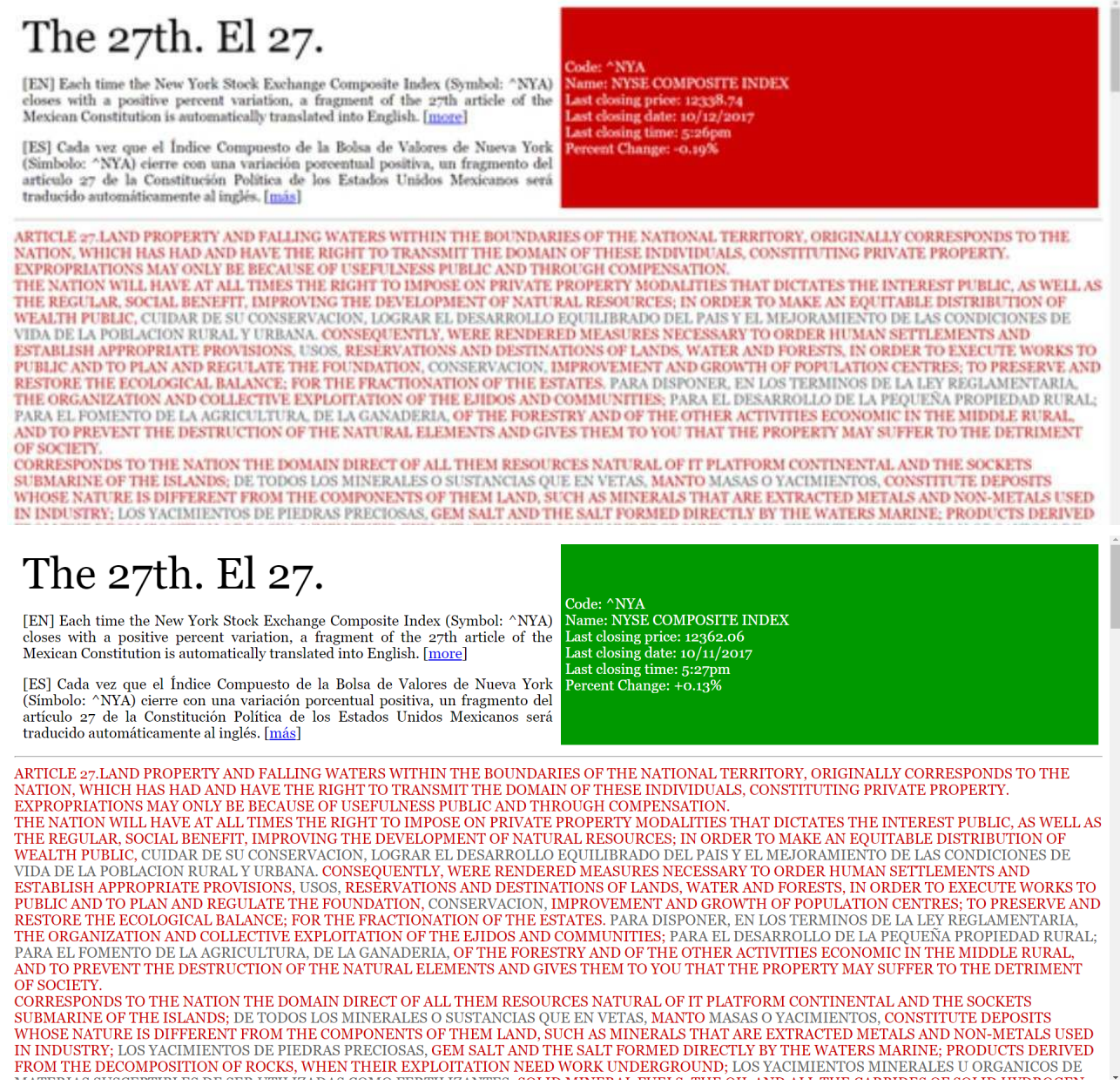

\section{[OCTUBRE DE 2017]}

EUgENIO TISELLI.

24 ¿Qué sucede cuando la lengua en que está escrita la ley se traduce maquínicamente a la lengua desconocida? The 27th // El 27 corroe, por un lado, la inmutabilidad de la ley en sí 
misma, mostrando que el mismo artefacto que sirve para calcular las ganancias del capital financiero, también puede ser expropiado y reubicado para visibilizar políticamente sus consecuencias. Y, por otro lado, la traductibilidad maquínica diluye la legitimidad de la ley como sustento discursivo. La ley abandona su funcionalidad en el momento mismo en que se incumple y se corrompe a favor del capital financiero que la explota. La letra se vuelve irreconocible y obsoleta primordialmente, por el incumplimiento con lo que se supone que legisla y no tanto por la falta de comprensión que involucra la migración al inglés. Por el contrario, lo que viene a hacer la traductibilidad maquínica es otorgarle un nuevo valor poético al desgaste a partir de una desviación crítica de ese vacío legal.

\section{Hacia una literatura fuera de sí}

Presentamos tres lecturas que apelan a planos integrados en la obra The 27th // El 27: la traductibilidad de los idiomas, la lengua de los cuerpos frágiles sobre los que rige la ley, la legalidad de la lengua legítima en tiempos de necrocapitalismo. Advertimos que las lenguas provocan desbordes y vinculaciones toda vez que se intenta desviar críticamente la técnica del poder mecanicista al que está sometida hacia las lindes de la poiesis como creación (Schmucler, 1996). En este sentido, apelamos a la insumisión artística mediante la cual la literatura consiste en una forma de posicionarse geopolíticamente desde la reflexividad técnica.

El propio Tiselli trae a colación la idea de interconexión entre el lenguaje artístico y la mediación técnica de la que se sirve su poética. Así se pregunta:

¿Podría el trabajo artístico ofrecer las herramientas necesarias para explicar las interconexiones de las cosas? Heidegger sugirió que pensáramos las cosas desde la perspectiva del arte como poiesis, es decir, el proceso a través del cual la esencia de las cosas se revela y se hace aparente. (Tiselli, 2012-2014 : p. 60).

Obras como The 27th // el 27 irrumpen en la escena intensificando la pregunta por el lugar que le cabe a la literatura en una sociedad maquínica, que establece con el lenguaje de la técnica un vaciamiento de su poder sígnico, y consecuentemente ideológico. El sitio de la falta, el afuera de la ley, sea literaria sea constitucional, consiste en desviar los propios dispositivos corrosivos que produce el mundo contemporáneo para reubicar a la poética tecnológica bajo la necesidad renovada de hacer hablar a los cuerpos enmudecidos.

\section{BIBLIOGRAFÍA}

APPADURAI, Arjun, La modernidad desbordada. Dimensiones culturales de la globalización, México, Trilce-FCE, 2001.

AAVV, "Sobre la poesía maquinal, o escrita por máquinas. Un manifiesto para la destrucción de los poetas", 2006-2016, http://www.motorhueso.net/text/pm.php, [consulta: 29-08-2016]. 
BREA, José Luis, “Algunos pensamientos sueltos acerca de arte y técnica” en La era postmedia. Acción comunicativa, prácticas (post)artísticas y dispositivos neomediales, Salamanca, Editorial Centro de Arte de Salamanca, 2002.

BERARDI, Franco (Bifo), La sublevación, Buenos Aires, Hekht Libros, 2014.

BUCK MOORS, Susan, “Capítulo III: Los mundos soñados de la cultura de masas”, en Mundo soñado y catástrofe. La aparición de la utopía de masas en el Este y el Oeste, Madrid, Antonio Machado Libros/La balsa de la medusa, 2004, pp. 59-154.

EMMELHAINZ, Irmgard, “Necrocapitalismo y arte contemporáneo”, en Blog Salon Kritic, 27 de junio de 2015, http://salonkritik.net/10-11/2015/06/necrocapitalismo_y_arte_contem_1.php, [consulta: 30-08-2016].

HOBSBAWM, Eric, “The Machines Breakers”, en Past and Present Oxford Journal, 1 (1): 57-70, 1952.

KOZAK, Claudia (Comp.), "Los límites de la literatura. Una introducción” y “Literatura visual urbana”, en Deslindes. Ensayos sobre la literatura y sus límites en el siglo XX, Rosario, Beatriz Viterbo, 2006, 11-22 y 141-152.

KOZAK, Claudia (Comp.), "Del modo de existencia de los objetos técnico-literarios. Pequeño diccionario personal ilustrado de literatura digital", 2013, e-book: Jorge Panesi y otros. IX Argentino de Literatura, Santa Fe, UNL, 2014, pp. 51-62, http://www.fhuc.unl.edu.ar/centros/ cedintel/argentino.pd, [consulta: 06-05-2017].

KOZAK, Claudia (Comp.), "Latin American Electronic Literature: When, Where and Why" en María Mencía (ed.). \#WomenTechLit, West Virginia University Press, Morgantown, WV, USA, 2017, pp. 55-72.

KOZAK, Claudia (Comp.), (Ed.), Tecnopoéticas argentinas. Archivo blando de arte y tecnología, Buenos Aires, Caja Negra Editora, 2015, 2da edición.

MARX, Karl, “La llamada acumulación originaria” en El capital (Tomo 1). México: Fondo de Cultura Económica, 2004, pp. 891-954.

PORTINARO, Pier Paolo, "El mito del poder absoluto", en Estado. Buenos Aires: Nueva Visión, 2003, pp. 53-79.

SCHMUCLER, Héctor, “Apuntes sobre el tecnologismo o la voluntad de no querer”, en Revista Artefacto, $\mathrm{n}^{\circ} 1$, Buenos Aires, diciembre de 1996.

SILVA BARROS, Luis, "The negative markets of necrocapitalism: an economic model of security goods and trades”, en Arizona Journal of Interdisciplinary Studies, Volume 1, Spring 2012, pp. 54-67.

TISELLI, Eugenio, "La magia de los números"; “Caminos para salir de la caverna: hacia un laboratorio a cielo abierto" y "The 27th // El 27", en Medios alternativos, 2012-2014, pp. 18-32, 54-78 y 129-134, http://www.motorhueso.net/text/medios_alternativos_tisselli.pdf, [consulta: 29-08-2016].

\section{NOTAS}

1. El artículo original de la Constitución de los Estados Unidos Mexicanos, nombre oficial de México, se encuentra disponible online en: http://info4.juridicas.unam.mx/ijure/fed/9/28.htm? $\mathrm{s}=$, [consulta: 22-08-2016]. 
2. Al respecto, se advierte que durante los siglos XVIII y XIX confluyen fenómenos que cambian radicalmente las condiciones materiales de vida de la gran mayoría del mundo europeo occidental: la Revolución Industrial, la Revolución Francesa, la conformación y expansión de grandes potencias europeas. Tales cambios se sucedieron en la escena geopolítica que podríamos considerar a primera vista abstracta pero que involucró modificaciones en la materialidad más llana y concreta del hombre europeo de la época: migraciones del campo a la ciudad, aceleramiento de las comunicaciones, desarrollo de medios de transporte, alfabetización masiva, entre otros enormes cambios que influyeron decisivamente para el desarrollo de un modo de producción capitalista.

3. Si bien Tiselli se refiere a los desvíos que se provocan en las máquinas por exceso, el hecho de utilizar la máquina para inducir un error, conceptualmente nos recuerda las revueltas surgidas en la primera mitad del siglo XIX con el movimiento ludita. En contra del desarrollo técnico que prometía progreso industrial en detrimento de magros salarios, despidos y desaparición del artesanado, la estrategia de los luditas fue introducir pequeñas roturas en las máquinas que ellos mismos manejaban, sublevándose a la producción fabril, en principio en el rubro textil: "Perhaps the most effectual manner in which the combination could coerce them was their former manner of carrying on war by destroying their frames.' In a domestic system of industry, where small groups of men, or single men, work scattered in numerous villages and cottages, it is, in any case, not easy to conceive of any other method which could guarantee an effective stoppage" (Hobsbawm, 1952: p. 61).

4. Y en línea con esto, se plantea una paradoja. Podemos decir que la obra debe su existencia justamente al incremento de la inequidad del necrocapitalismo contra el que se revela. Así, supongamos que éste virara rotundamente en baja hasta desaparecer, también sería el fin de la funcionalidad de la obra en sí misma.

\section{RESÚMENES}

En este trabajo analizamos el uso político de lenguajes -verbal, visual, algorítmico- en diversos discursos que integran The 27th // El 27 de Eugenio Tiselli (2014). Argumentamos en torno a tres lecturas posibles propias de la cultura visual global contemporánea. Primeramente, advertimos el uso dual y subordinado de idiomas como símbolo de apropiación de la Nación mexicana, modificándose con cada palabra traducida, su órgano máximo de orden legal, la Constitución. En segundo lugar, el lenguaje visual en el que aparece el texto en dos colores, negro (base en español) y rojo (cambios en inglés), emula en la traducción la perforación de un cuerpo "viviente". Por último, proponemos una lectura sobre el lenguaje algorítmico necrocapitalista en relación con la propiedad privada.

Dans ce travail, nous analysons l'usage politique du langage -verbale, visuel, algorithmique- dans des discours du The 27th // El 27 Eugenio Tiselli (2014). Premièrement, nous observons l'usage dualiste et subordonné des langues conformant le symbole de l'appropriation de la Nation mexicaine. En deuxième lieu, le langage visuel par lequel le texte apparait en deux couleurs, noir (base en espagnol) et rouge (changement en anglais). Enfin, nous proposons une lecture sur la langue algorithmique nécrocapitaliste par rapport à la propriété privée. 
ÍNDICE

Mots-clés: langages, politique, littérature numérique, Mexico, necrocapitalisme, migrations, The 27th // El 27

Palabras claves: lenguajes, política, literatura electrónica, México - necrocapitalismo, migraciones, The 27th // El 27

\section{AUTOR}

VERÓNICA PAULA GÓMEZ

CEDINTEL, FHUC, Universidad Nacional del Litoral - CONICET

Literatura electrónica y Ciencia Política

veronicagomez[at]conicet.gov.ar 